\title{
Design and Performance of Trombe Wall with Humidification for Air Cooling in Hot Arid Regions
}

Mahmoud A. El-Sherief ${ }^{1}$, Hany. A. Mohamed ${ }^{2}$, M. Salem Ahmed ${ }^{3 *}$

${ }^{1,2}$ Department of Mechanical Engineering, Assuit University, Assuit, Egypt

${ }^{3}$ Faculty of Technology and Education, Sohag University, Sohag, Egypt

DOI: $10.36347 /$ sjet.2020.v08i08.002

| Received: 30.07.2020 | Accepted: 07.08.2020 | Published: 13.08.2020

*Corresponding author: M. Salem Ahmed

Abstract

Review Article

In this work a solar chimney with the aid of a humidifier located in opposite wall is applied as a passive solar technique for cooling building in arid regions. A test room was made from wood material except for the south wall, Trombe Wall; it is composed of a commercial glass wall apart from masonry thick wall with $10 \mathrm{~cm}$ gap. The experiments were carried out on summer in the arid region along the day hours with and without humidification process. The experimental observations show a reduction in room temperature, reaches to $8^{\circ} \mathrm{C}$. The experimental results show an increase in natural air ventilation, with air velocity reaches to $1.6 \mathrm{~m} / \mathrm{s}$. Therefore, human thermally comfortable indoor environment for many hours during hot summers is achieved. The present study shows a Trombe wall with a movable air gap is recommended for the human comfortable along the day hours.

Keywords: Trombe Wall, Solar Chimney, Natural Ventilation.

Copyright @ 2020: This is an open-access article distributed under the terms of the Creative Commons Attribution license which permits unrestricted use, distribution, and reproduction in any medium for non-commercial use (NonCommercial, or CC-BY-NC) provided the original author and source are credited.

\begin{tabular}{|c|c|c|}
\hline \multicolumn{3}{|c|}{ Nomenclature } \\
\hline $\mathbf{T}$ & Temperature & {$\left[{ }^{0} \mathrm{C}\right]$} \\
\hline $\mathrm{RH}$ & relative humidity & {$[\%]$} \\
\hline $\mathrm{V}$ & air velocity & {$[\mathrm{m} / \mathrm{s}]$} \\
\hline \multicolumn{3}{|c|}{ Subscript } \\
\hline gap & air gap & {$\left[{ }^{\circ} \mathrm{C}\right]$} \\
\hline $\mathrm{gb}$ & gap bottom space & \\
\hline gm & gap middle space & \\
\hline go & glass outside & \\
\hline $\mathrm{gu}$ & gap upper space & \\
\hline out & ambient air & \\
\hline
\end{tabular}

\section{INTRODUCTION}

Today, natural ventilation is not only regarded as a simple way to provide fresh air for then occupants, necessary to maintain acceptable air-quality levels but also as an excellent energy saving way to Corresponding author: mahmoudsalem.ahmed@yahoo.com (M. Salem Ahmed) reduce the internal cooling load of housing located in the hot region. Since, the energy resources are getting reduced and to have seemed a big problem in the world. Depending on the ambient conditions, natural ventilation can be led to indoor thermal comfort without mechanical cooling being required. Ventilation improves thermal comfort by replacing hot humid air near the occupants with fresh air and improves the air quality by reducing the impurity [1].

The preferred air velocity increases with increase in air temperature and humidity [2]. In the recent days, passive solar energy is considered one of the best solutions to the energy crises and also, it is clean and eco-friendly [3].

Passive structures like a solar chimney or building openings can aid in achieving the required ventilation rate as in Fig. 1. Insufficient ventilation results in the illness of occupants $[4,5]$. Evaporative coolers cool the air, water or both by evaporating a very small portion of water. They are suitable for arid 
regions [6] but not suitable for humid regions and low humidity applications. Air washer, humidifier, roof surface evaporative cooler [7] and passive downdraft evaporative cooler [8] are few examples of evaporative coolers. Water, which gets cooled in evaporative coolers, can be used to cool spaces with the aid of cooling system [9]. Thermal comfort achieving using evaporative cooling has been studied extensively [8]. A passive evaporative cooler in use at Ahmedabad, India, achieved average and peak indoor temperatures $5 \mathrm{oC}$ and $10-14$ oC lower than the average and peak outdoor temperatures during the summer month of April, an annual energy saving of $64 \%$ over conventional air conditioning and $36 \%$ saving in maintenance expenses[7]. Evaporative coolers can be coupled with other passive systems like earth tunnel cooling (MAIYA) and ventilation cooling [10] for better performance.

The solar chimneys principle is simple: the sun heat gives to passing air, which expands going into a gap between the glass and masonry wall, according to the buoyancy principle: "hot air rises". By this way, the air is drawn from the room through the bottom hole achieving the ventilation process [11]. Solar chimney with Trombe Wall provides passive cooling and it can lead to a reduction of the energy consumption in buildings for hot regions [13, 14, 15]. Schematic diagrams of the solar chimney and the human comfort group are shown in Figures 1 and 2.

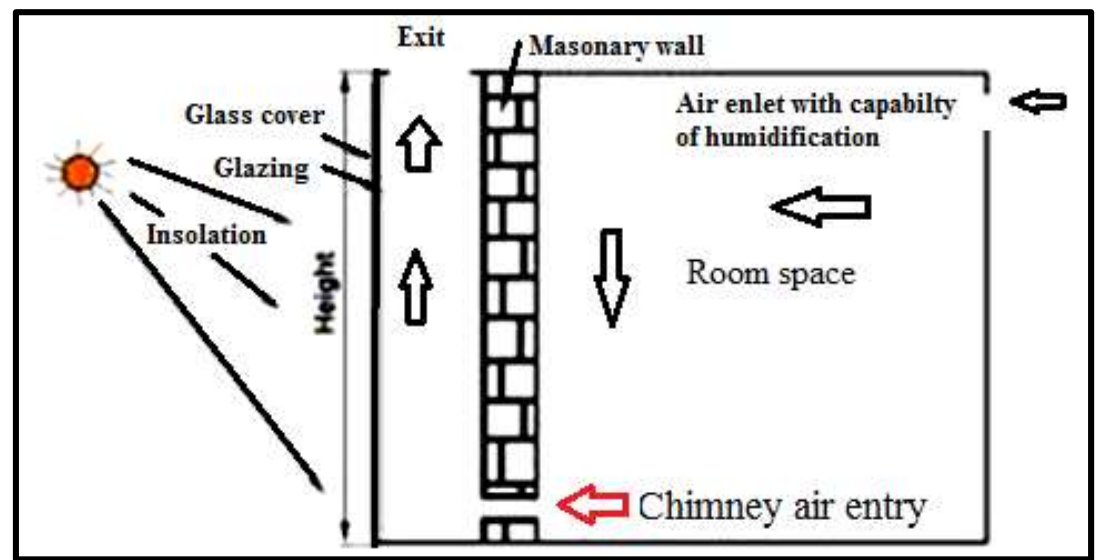

Fig-1: Schematic drawing of Solar Chimney

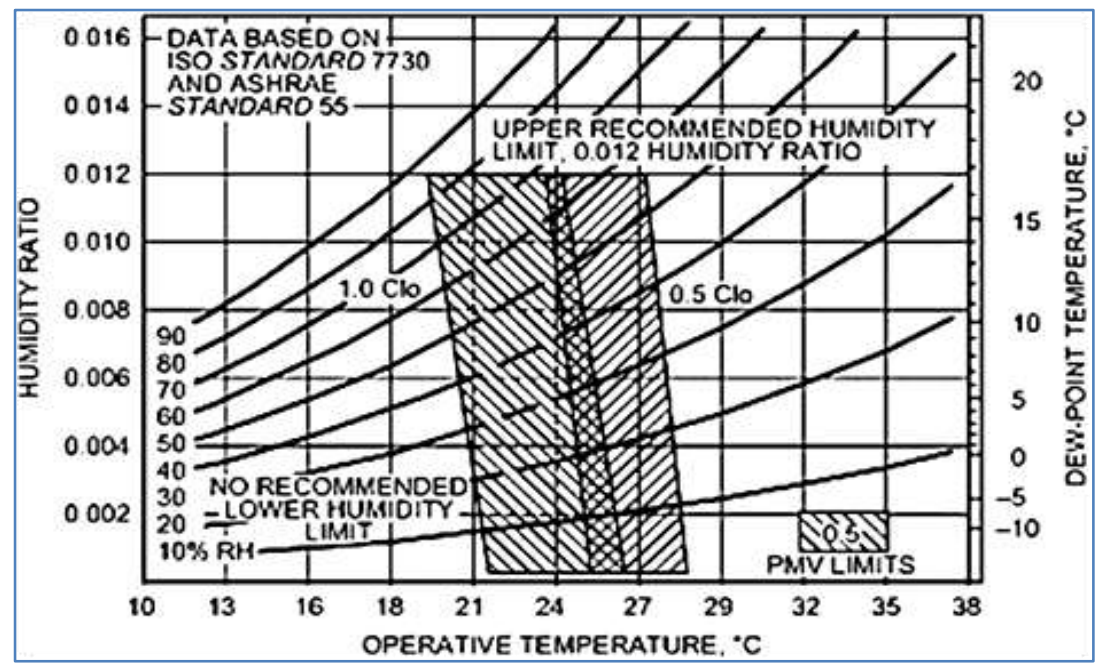

Fig-2: Human comfort range (ASHRAE)

Trombe walls are viewing as passive energy in which provides energy to the internal buildings without using any mechanical energy. They are built from available materials at the constructed regions and they introduced added benefit through the heat emitted by radiation in the form of infrared as more penetrating and better than the conventional convective forced air heating systems. In the solar chimney, due to the difference in density between cool air and warmer air, warm air tends to move upward and escape due to its lower density. This air movement can lead to a stack effect driven by buoyancy. As long as there is a continuous source of heat and a considerable amount of cool air available, a constant stream of air is produced. The higher in the temperature difference and the height of the building cause a greater buoyancy force. This leads to greater air movement. Many configurations of solar chimneys were used widely in the past and many are being developed again today[11, 17, 18] Amer). 
Several studies were carried out on this topic(Joseph Khedari et al.J. Khedari et al. Hirunlabh et al. [23, 24].

The interest of passive solar cooling was increased in the last years, mainly for economic and environmental reasons[25, 26]. Using a Trombe Walls for summer cooling, the ventilation rate increases with the increase of surface wall temperature[11]. A solar energy absorbed with an open top and bottom, when solar radiation impinges on the building, was studied by[27]. The predicted heat transfer rate increases with the channel and the massive wall surface heat flux [28]. A reverse flow can be observed at the outer when the chimney gap increased to a certain value [29]. Although it is a very well-known system and widely studied, management of solar energy, its heat, and fluid flows mechanisms and the design consideration of the system of Trombe Walls including fabrication materials to optimize the ventilation process need more experiments and research[30, 31]. In this study, a test room is built and the system of Trombe Wall is incorporated to the test room. Experimental work is designed to simulate and test the performance of a Trombe Wall incorporated to the test room for cooling processes. The effect of air humidifier on both the test room temperatures and the induced ventilations are studied. The effect of the humid air has been studied numerically on the performance of the vertical solar chimney. Simulated between dry and wet air in a range of $30-80 \%$ and heat transfer in a solar chimney were conducted. The results revealed that water vapor should be considered in the application of a solar chimney. To increased ventilation and reduced reverse flow upon opening, an aspect ratio of 14:1 and a fixed opening height are recommended for solar chimneys with moist air [32].

\section{EXPERIMENTAL WORK}

The room was made from wood material except for the south wall which was known as Trombe Wall. It is composed of a commercial glass wall apart from masonry thick wall, $40 \mathrm{~cm}$, with a small gap of 10 $\mathrm{cm}$. This side represents a system of Trombe Walls and glazing oriented to the south direction for capturing the solar gain during the sun time. The wooden room is well internally insulated. Tests are performed with the aid of humidification process. The experiments are carried out on summer at the arid valley. Measurements of temperatures, velocity, and humidity using different instruments were monitored at different locations in the room and in the Trombe Wall system. Figure 3 (a and b) shows a photograph of the experimental set up and measuring temperatures at different positions.

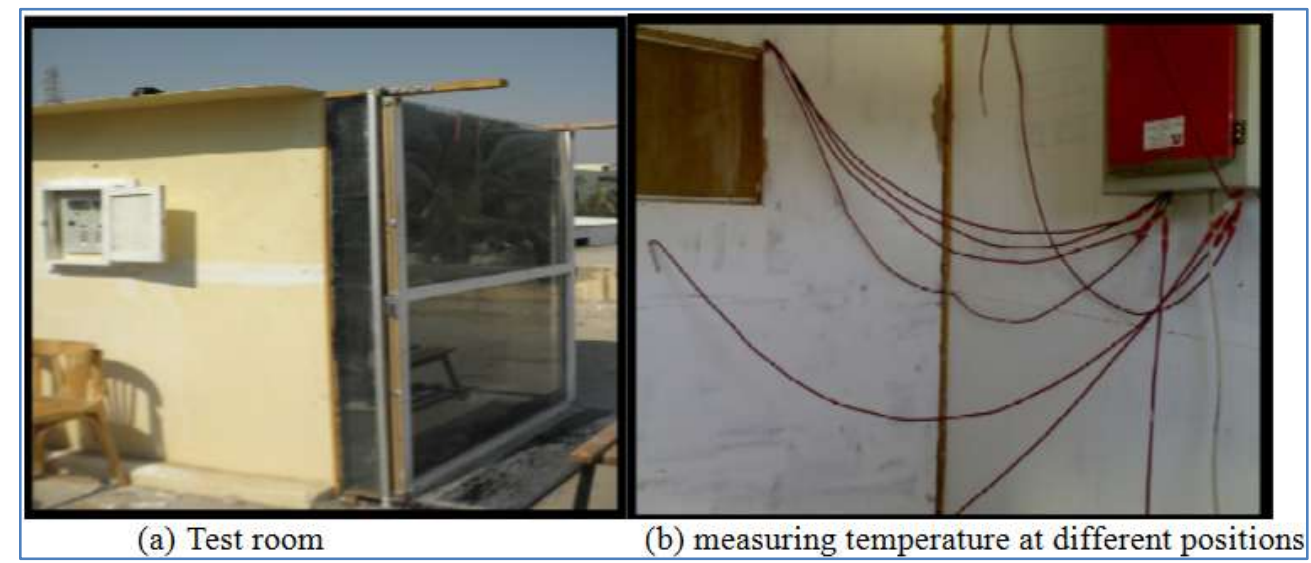

Fig-3: Photograph of the experimental set up

\section{Experimental Set-Up}

The overall dimensions of the wooden room are $2.5 \mathrm{~m}$ (length) $\times 1.7 \mathrm{~m}$ (width) $\times 2.2 \mathrm{~m}$ (height). The system of Trombe Wall oriented composed from a masonry wall constructed from a brick material having the potential to thermal storage for solar transmitted, 40 $\mathrm{cm}$ width. A glass wall is stand in the front of the masonry wall at $10 \mathrm{~cm}$ space, an air gap. This gap allows air to circulate from the test room interior to the ambient for ventilation. There is an upper opening window, $0.3 \mathrm{~m} \times 0.5 \mathrm{~m}$, in the north wall facing to the Trombe Wall. The glass wall is composed of two parts, the upper part has $57 \mathrm{~cm}$ height and the down has 2.05 $\mathrm{m}$ height. This makes an opening at the top of the air gap channel to allow the air escaping out from the solar chimney. A water washer humidifier located through this window. The opening window allows the entry of air into the room. The glass wall is commercial clear glass with $5 \mathrm{~mm}$ thickness.

\section{Measurements and Uncertainties}

Air temperature, humidity, speed, and surface walls temperature measurements were taken at different locations as in Figure 4. Temperatures were measured in eight different locations, as in Figure 4, using PT-100 sensors with an accuracy of $\pm 0.5^{\circ} \mathrm{C}$ (three points in an air gap; one point in the middle of the test room, one point on the surface of the glass wall, and two points on the front and back surfaces of the building wall and one point to measure the ambient temperature). 
Point temperature sensors in the glass wall and in the air gap points of the sun are protected with small pieces of aluminum foil. Air velocities were measured across the air gap using an anemometer with an accuracy of $\pm 0.1 \mathrm{~m} / \mathrm{s}$. The relative humidity of air in the surrounding and in the interior of the test chamber was measured using a $\pm 0.2 \mathrm{RH}$ humidity device. The measurements were taken from 8:00 in the morning until 8:00 in the evening.

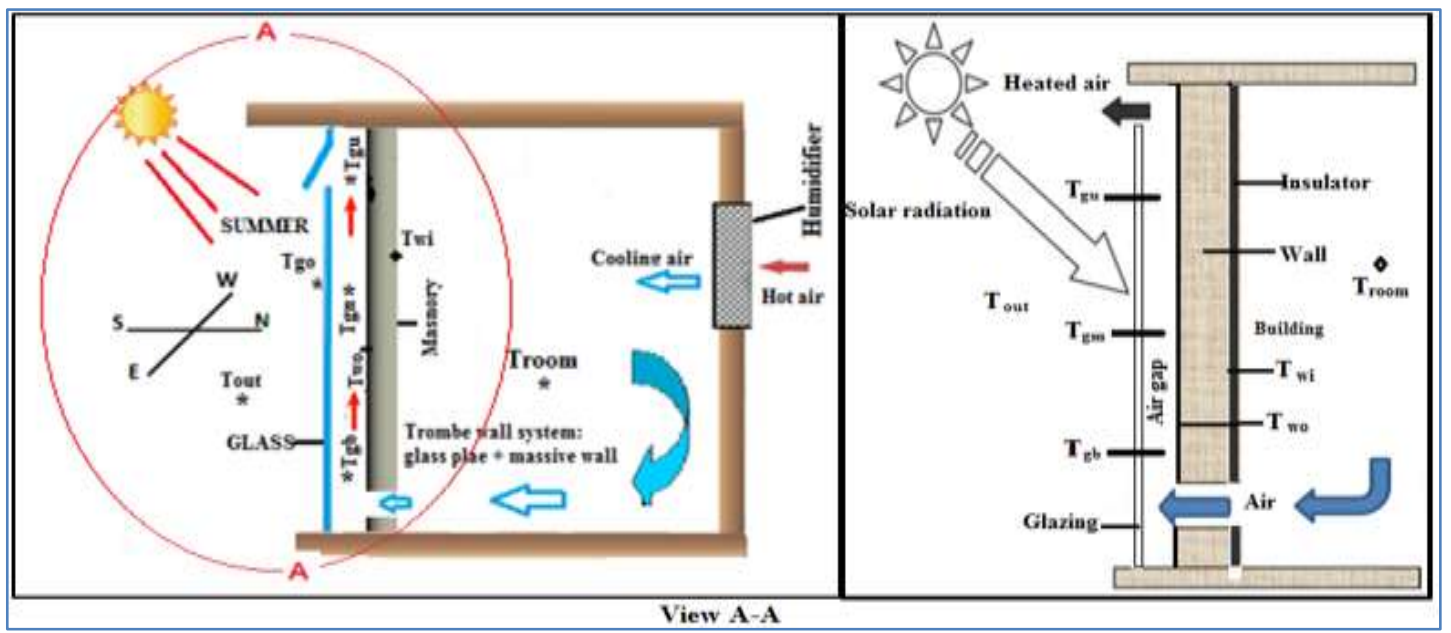

Fig-4: Schematic drawing of the general view of the test room with the Trombe Wall.

\section{RESULTS AND DISCUSSIONS}

Figure 5 shows the temperatures measurements, at $10 \mathrm{~cm}$ air gap width, along the day

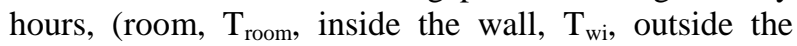
wall, $\mathrm{T}_{\text {wo }}$, gap upper space, $\mathrm{T}_{\mathrm{gu}}$, gap middle space, $\mathrm{T}_{\mathrm{gm}}$, gap bottom space, $\mathrm{T}_{\mathrm{gb}}$, outside glass, $\mathrm{T}_{\mathrm{go}}$, and ambient, $\mathrm{T}_{\text {out }}$ ), with humidification process. The variation of these temperature values along the day hours approximately linear increase to a peak value at 14 or 15 PM then approximately linear decrease till 20 PM as shown in Fig 5. These variations are normally expected according to the basics of heat transfer and heat incident by the sun irradiation. It is found that the room temperature is less than the outside temperature as shown in Fig 5 due the solar chimney effect. The effects of the humidification process are discussed below. The results in the case with humidification show a significant reduction in the room temperatures compared to the out room along the day hours.

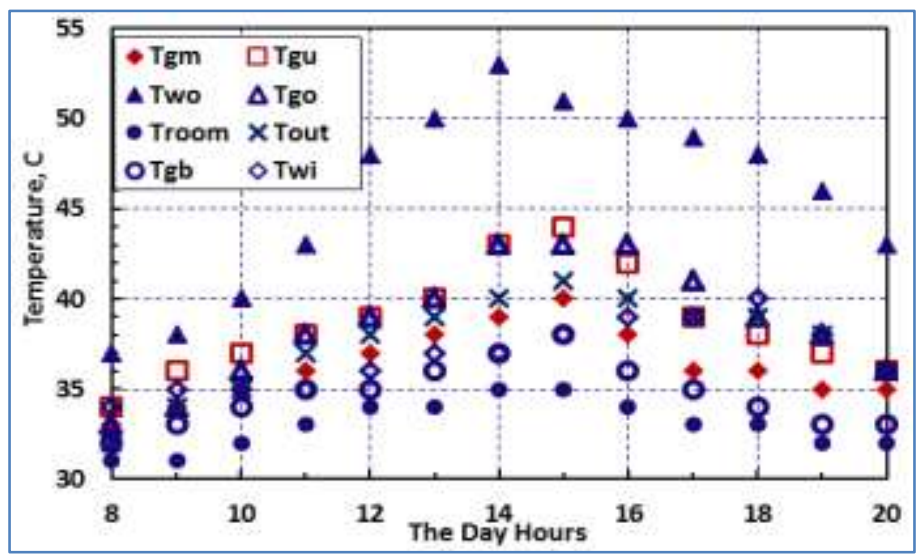

Fig-5: All measured temperatures along the day hours with humidification process

\section{Variation of Air Gap Temperature}

Figure 6 shows the discrepancy in air temperatures across the solar chimney, and the air gap, throughout the daylight hours, compared to the external temperatures of the corresponding building wall and ambient temperatures using the humidification process. It is clearly shown that the air temperatures through the gap gradually increase from the bottom to the upper position $\left(\mathrm{T}_{\mathrm{gb}}<\mathrm{T}_{\mathrm{gm}}<\mathrm{T}_{\mathrm{gu}}\right)$. This observation agrees with the buoyancy law. So, stream flow of air through the chimney gap would be created from the bottom to the upper casing through the air gap. Therefore, air naturally flows from the room to the gap creating ventilation process inside the room. The figures also show remarkable increase in the outside masonry wall temperature surface $\left(\mathrm{T}_{\mathrm{wo}}\right)$ compared with the ambient $\left(\mathrm{T}_{\text {out }}\right)$, and the air gap temperatures at three positions, $\left(\mathrm{T}_{\mathrm{gu}}, \mathrm{T}_{\mathrm{gm}}, \mathrm{T}_{\mathrm{gb}}\right)$. This remarkable increasing at the outside wall temperature increases the conduction heat transfer through the masonry wall. From the other hand, 
this increases in the wall temperature may assist for increasing the air flow velocity through the gap causing an enhancement in the room ventilations. Thus, well insulated the back side of the masonry wall should be done for the solar chimney which reduces heat convection to room as shown in Fig.4 (view A-A).

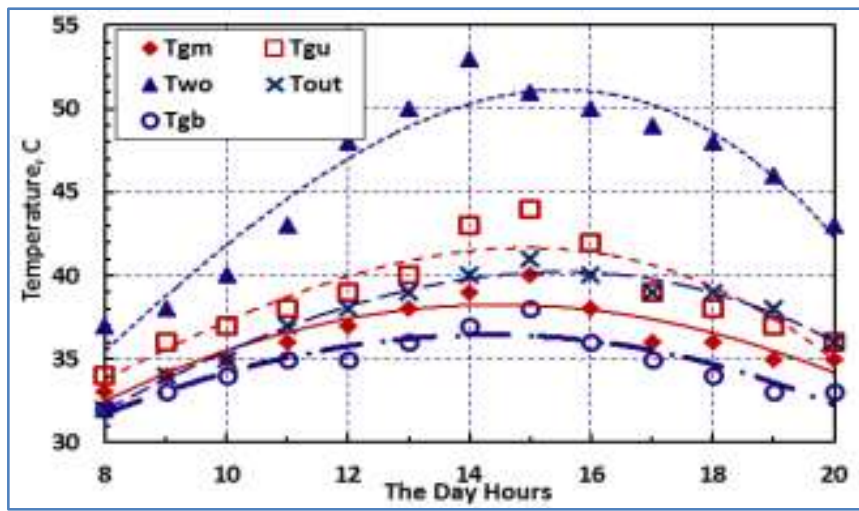

Fig-6: Measured temperatures through the air gap along the day hours with humidification process

\section{Variation of Masonry and Glass Wall Temperatures}

Figure 7 shows the measured values of ambient $\left(\mathrm{T}_{\text {out }}\right)$, the air gap $\left(\mathrm{T}_{\mathrm{gm}}\right)$, the outer wall $\left(\mathrm{T}_{\mathrm{wo}}\right)$, the inner wall $\left(\mathrm{T}_{\mathrm{wi}}\right)$, and room $\left(\mathrm{T}_{\text {room }}\right)$ temperatures at the chimney middle level along the day hours. These figures are mainly presented to show the remarkable reduction in the conduction heat transfer, $\mathrm{T}_{\mathrm{wo}} \gg \mathrm{T}_{\mathrm{wi}}$, due to well insulated of the back side of the masonry wall. This shows that the present experimental test rig was built with accepted quality.

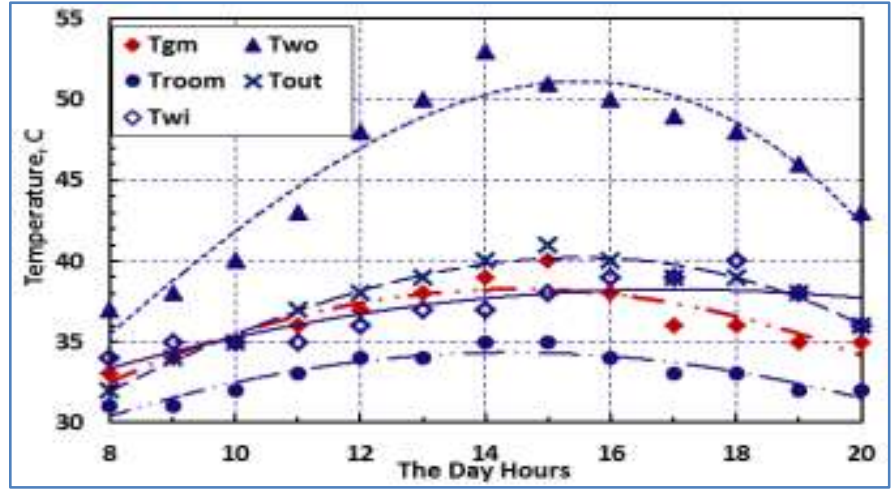

Fig-7: Measured temperatures through the air gap along the day hours with humidification process

\section{Variation Air Velocity through the Solar Chimney}

The variation of air velocity through the solar chimney, $\mathrm{V}_{\text {gap }}$, and the corresponding $\mathrm{T}_{\text {out }}, \mathrm{T}_{\mathrm{gm}}, \mathrm{T}_{\mathrm{wo}}$, and Troom measured temperatures along the day hours are shown in Fig 8. It is clearly shown in the case with humidification as in Fig. 8, gradually increase the air velocity till 16 o'clock then gradually decrease till 20
PM. The increasing and decreasing the air velocity is attributed due to the buoyancy action resulted from the increase and decrease the chimney temperatures. This observation ensures the ability of the solar chimney to create a ventilation process through the test room. The experimental results also show an increase in natural air ventilation, with air velocity reaches to $1.6 \mathrm{~m} / \mathrm{s}$.

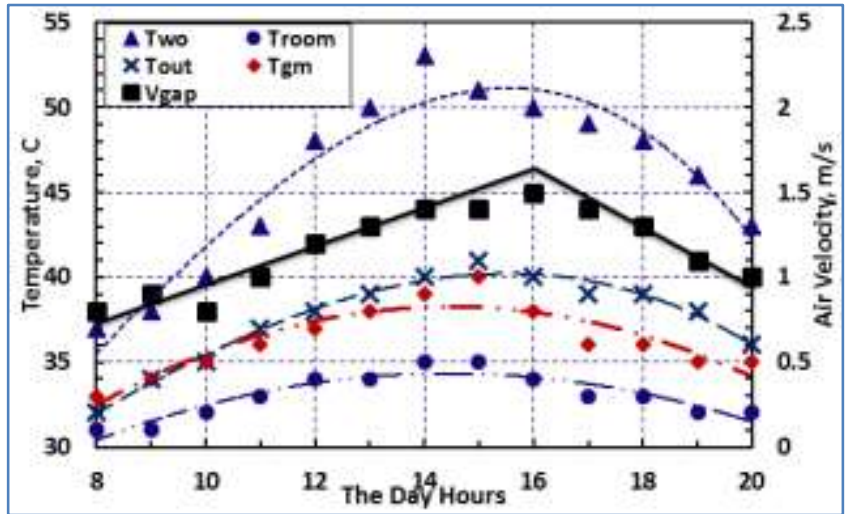

Fig-8: Solar chimney air velocity, $V_{\text {gap }}, T_{\text {out }}, T_{\text {gm }}, T_{\text {wo }}$, and Troom along the day hours with humidification process. 


\section{Variation of Air Relative Humidity inside the Room}

Figure 9 shows the air relative humidity inside the test room, $\mathrm{Rh}_{\mathrm{i}}$, compared the ambient relative humidity, $\mathrm{Rh}_{\mathrm{o}}$, along the day hours with humidification process. It is clearly shown higher increase into room relative humidity with humidification process. Since the ambient air relative humidity is too low, thus humidification process should be recommended for human comfortable.

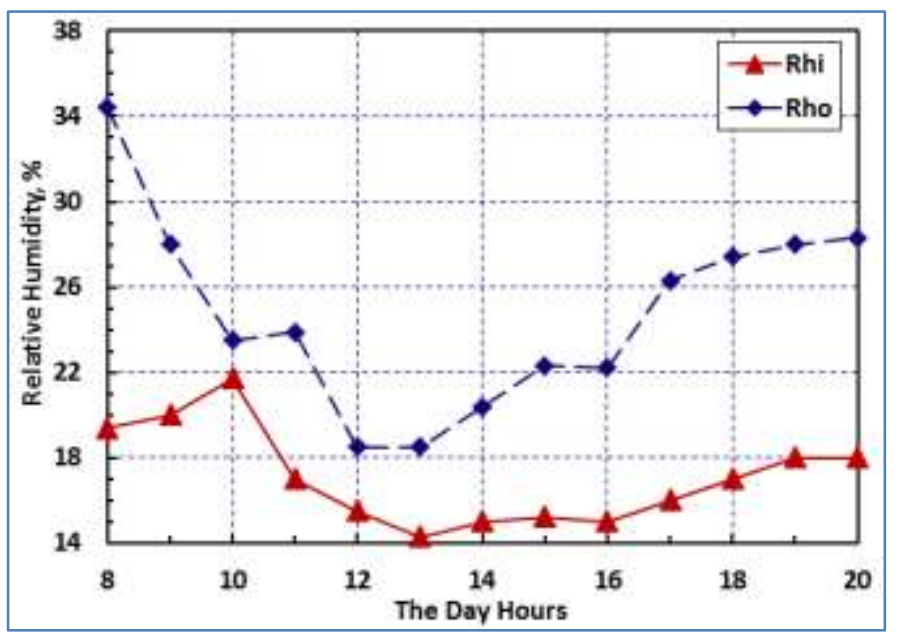

Fig-9: Measured the air relative humidity inside the room along the day hour with humidification process

\section{Variation of the Heat Transfer Rate}

Figure 10 shows an air temperature profile through the heat transfer path, Tout, Two, Twi, and Troom all daylight hours. Since the heat transfer region and heat transfer coefficients remain almost constant throughout all experimental measurements due to small differences in air velocity along the heat pathway. Therefore, the temperature difference between the outer and inner side of the construction wall temperatures, (Two-Twi), represents the rate of heat transfer to the room. Therefore, Figure 11 has been adapted to represent the rate of heat transfer to the room throughout the day in the event of a humidification process. It turns out that the heat transfer rate increases until 14:00 and then decreases to remain daylight hours. This means that room temperatures are affected more quickly by the ambient temperatures of the solar chimney as a result of using humidity in most of the day.
This means that room temperatures are affected more quickly by the ambient temperatures of the solar chimney as a result of using humidity in most of the day.

Alternatively, Figure 12 shows the difference between ambient and room temperature (which is the total heat transfer). As shown in the figure, the difference in ambient temperature and room temperature continues to increase significantly until 15 o'clock and then down to be fixed from 15 o'clock until 19 o'clock where the difference between the exit and room temperature is approximately constant as shown in Figure 5. After 19:00 the difference (Tout - Troom) decreases as the temperature is low at night. This decrease in temperature difference may be attributed to the relative humidity values. This means that a solar chimney can be recommended for humidification to achieve passive Cooling.

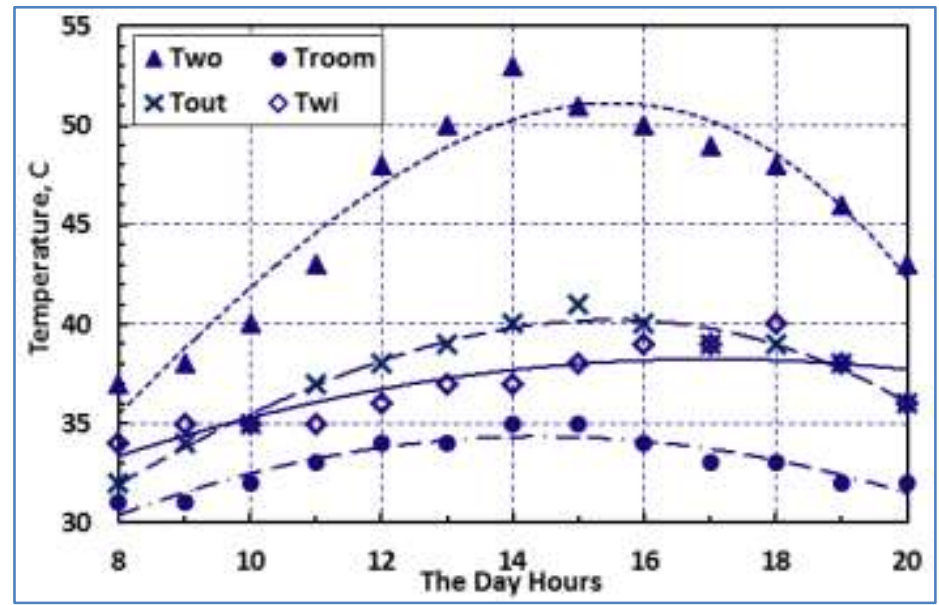

Fig-10: Wall and room temperatures along the day hour with humidification process 


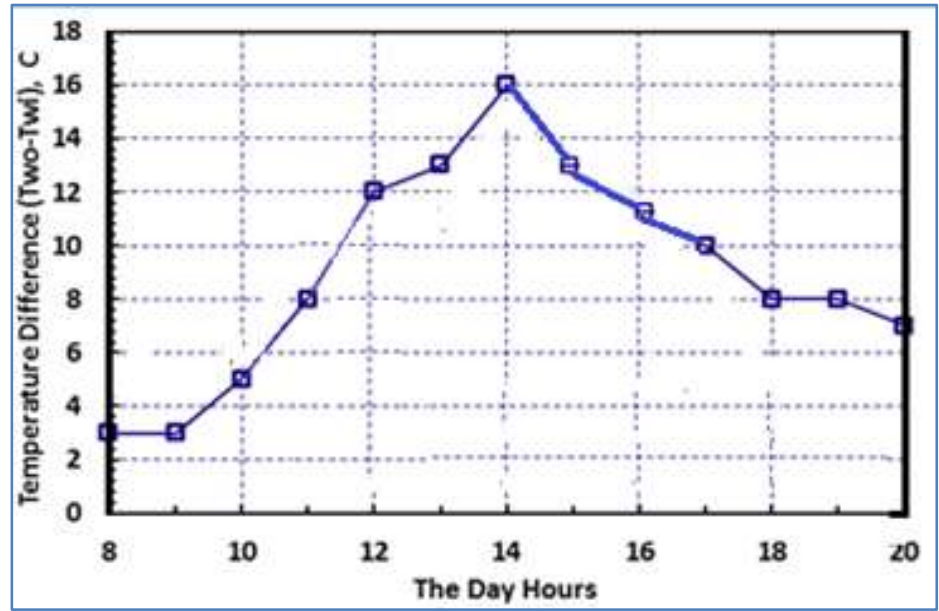

Fig-11: Measured temperatures difference $\left(\mathbf{T}_{\mathrm{wo}} * * \mathbf{T}_{\mathrm{wi}}\right)$ along the day hours with humidification

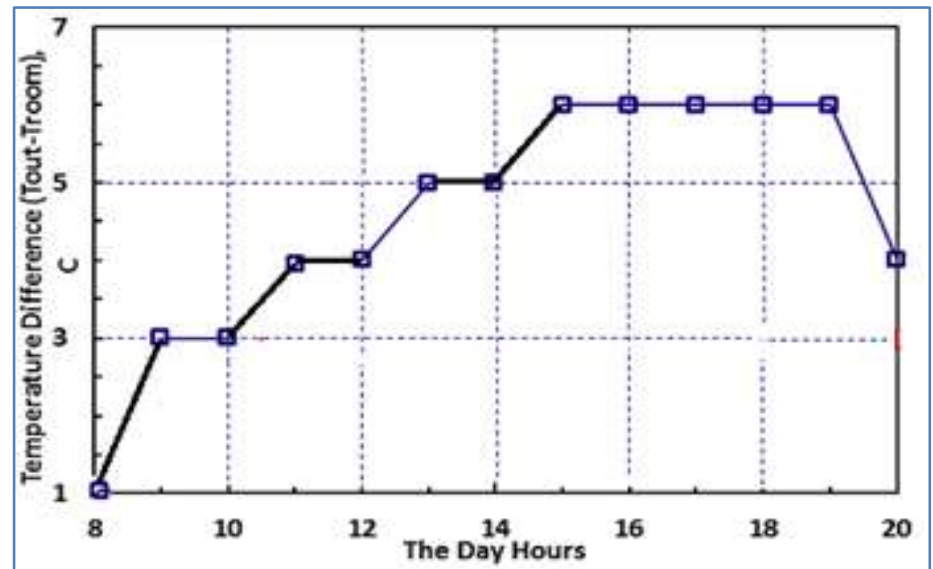

Fig-12: Measured temperatures difference $\left(T_{\text {out }} * * T_{\text {room }}\right)$ along the day hours with humidification

\section{CONCLUSIONS}

Using solar chimney with the aid of a humidifier located in opposite direction as the passive solar technique can be recommended for cooling building in arid regions. Important aspects can be realized from the present work:

1. The remarkable reduction in the conduction heat transfer, Two > Twi, due to well insulated of the back side of the masonry wall shows that the present experimental test rig was built with accepted quality.

2. Using this technique, the interior room can be maintained at a temperature lower than the ambient, with difference reaches to $8^{\circ} \mathrm{C}$, with small variations along the day period. So, thermally comfortable indoor environment for many hours during hot summers can be achieved.

3. The experimental results show an increase in natural air ventilation, with air velocity reaches to $1.6 \mathrm{~m} / \mathrm{s}$. Thus, a natural ventilation system that improves air quality and thermal comfort levels in a single story building can be created by using this technique.

4. The Comparisons between the results obtained for the Trombe wall with $5 \mathrm{~cm}$ and $10 \mathrm{~cm}$ air gaps show best human comfortable till 15 o'clock for $5 \mathrm{~cm}$ air gap while the Trombe wall with $10 \mathrm{~cm}$ air gap gives better results to the day end. So, a Trombe wall with a movable air gap is recommended for the human comfortable along the day hours.

\section{REFERENCES}

1. Sekhar SC, Goh SE. Thermal comfort and IAQ characteristics of naturally/mechanically ventilated and air-conditioned bedrooms in a hot and humid climate. Building and Environment. 2011 Oct 1;46(10):1905-16.

2. Cândido C, De Dear RJ, Lamberts R, Bittencourt L. Air movement acceptability limits and thermal comfort in Brazil's hot humid climate zone. Building and environment. 2010 Jan 1;45(1):222-9.

3. Heinrich J. Influence of indoor factors in dwellings on the development of childhood asthma. International journal of hygiene and environmental health. 2011 Jan 1;214(1):1-25.

4. Balaras CA, Dascalaki E, Gaglia A. HVAC and indoor thermal conditions in hospital operating rooms. Energy and Buildings. 2007 Apr $1 ; 39(4): 454-70$.

5. Nahar, N. M., Sharma, P., \& Purohit, M. M. (2003). Performance of different passive techniques for cooling of buildings in arid regions. Building and Environment, 38(1), 109. 116. 
6. Wanphen S, Nagano K. Experimental study of the performance of porous materials to moderate the roof surface temperature by its evaporative cooling effect. Building and Environment. 2009 Feb 1;44(2):338-51.

7. Ford B, Patel N, Zaveri P, Hewitt M. Cooling without air conditioning: The torrent research centre, ahmedabad, India. Renewable energy. 1998 Sep 1;15(1-4):177-82.

8. Lehmann B, Dorer V, Gwerder M, Renggli F, Tödtli J. Thermally activated building systems (TABS): Energy efficiency as a function of control strategy, hydronic circuit topology and (cold) generation system. Applied Energy. 2011 Jan 1;88(1):180-91.

9. Xuan YM, Xiao F, Niu XF, Huang X, Wang SW. Research and applications of evaporative cooling in China: A review (II)-Systems and equipment. Renewable and Sustainable Energy Reviews. 2012 Jun 1;16(5):3523-34.

10. Maerefat M, Haghighi AP. Natural cooling of stand-alone houses using solar chimney and evaporative cooling cavity. Renewable Energy. 2010 Sep 1;35(9):2040-52.

11. Gan G. A parametric study of Trombe walls for passive cooling of buildings. Energy and buildings. 1998 Feb 1;27(1):37-44.

12. Saadatian O, Sopian K, Lim CH, Asim N, Sulaiman MY. Trombe walls: A review of opportunities and challenges in research and development. Renewable and Sustainable Energy Reviews. 2012 Oct 1;16(8):6340-51.

13. Kasaeian AB, Molana S, Rahmani K, Wen D. A review on solar chimney systems. Renewable and sustainable energy reviews. 2017 Jan 1;67:954-87.

14. Mokheimer EM, Shakeel MR, Al-Sadah J. A novel design of solar chimney for cooling load reduction and other applications in buildings. Energy and Buildings. 2017 Oct 15;153:219-30.

15. Agrawal PC. Review of passive systems and passive strategies for natural heating and cooling of buildings in Libya. International Journal of Energy Research. 1992 Mar;16(2):101-17.

16. Zhai XQ, Song ZP, Wang RZ. A review for the applications of solar chimneys in buildings. Renewable and Sustainable Energy Reviews. 2011 Oct 1;15(8):3757-67.

17. Awbi HB. Design considerations for naturally ventilated buildings. Renewable Energy. 1994 Aug 1;5(5-8):1081-90.

18. Bansal NK, Mathur R, Bhandari MS. Solar chimney for enhanced stack ventilation. Building and environment. 1993 Jul 1;28(3):373-7.

19. Amer EH. Passive options for solar cooling of buildings in arid areas. Energy. 2006 Jul 1;31(89):1332-44.
20. Khedari J, Hirunlabh J, Bunnag T. Experimental study of a roof solar collector towards the natural ventilation of new houses. Energy and Buildings. 1997 Jan 1;26(2):159-64.

21. Khedari J, Kaewruang S, Pratinthong N, Hirunlabh J. Natural ventilation of houses by a Trombe wall under the climatic conditions in Thailand. International journal of ambient energy. $1999 \mathrm{Apr}$ 1;20(2):85-94.

22. Hirunlabh J, Kongduang W, Namprakai P, Khedari J. Study of natural ventilation of houses by a metallic solar wall under tropical climate. Renewable Energy. 1999 Sep 2;18(1):109-19.

23. Monghasemi N, Vadiee A. A review of solar chimney integrated systems for space heating and cooling application. Renewable and Sustainable Energy Reviews. 2018 Jan 1;81:2714-30.

24. Abdallah AS. Experimental study of passive air condition system integrated into a single room in Assiut, Egypt. Energy and Buildings. 2017 Oct 15;153:564-70.

25. Ruiz Á, Salmerón J, González R, Álvarez S. A calculation model for Trombe walls and its use as a passive cooling. InProceedings of International Conference Passive and Low Energy Cooling for the Built Environment, Santorini, Greece 2005 (pp. 365-369).

26. Onbasioglu H, Egrican AN. Experimental approach to the thermal response of passive systems. Energy conversion and management. 2002 Oct 1;43(15):2053-65.

27. Harris DJ, Helwig N. Solar chimney and building ventilation. Applied Energy. 2007 Feb 1;84(2):13546.

28. Li Y, Duanmu X, Sun Y, Li J, Jia H. Study on the air movement character in solar wall system. InProceedings: Building Simulation 2007 (pp. $927-$ 931).

29. Liping W, Angui L. A numerical study of Trombe wall for enhancing stack ventilation in buildings. InThe 23rd conference on passive and low energy architecture, Geneva, Switzerland 2006 Sep.

30. Ruiz-Pardo A, Domínguez SÁ, Fernandez JA. Revision of the Trombe wall calculation method proposed by UNE-EN ISO 13790. Energy and Buildings. 2010 Jun 1;42(6):763-73.

31. Goudarzi H, Mostafaeipour A. Energy saving evaluation of passive systems for residential buildings in hot and dry regions. Renewable and Sustainable Energy Reviews. 2017 Feb 1;68:43246.

32. Sudprasert S, Chinsorranant C, Rattanadecho P. Numerical study of vertical solar chimneys with moist air in a hot and humid climate. International Journal of Heat and Mass Transfer. 2016 Nov 1;102:645-56. 